INTERNATIONAL JOURNAL OF RESEARCHES IN BIOSCIENCES, AGRICULTURE AND TECHNOLOGY (c) VISHWASHANTI MULTIPURPOSE SOCIETY (Global Peace Multipurpose Society) R. No. MH-659/13(N) www.vmsindia.org

\title{
THERMO-ACOUSTIC INVESTIGATIONS ON L-VALINE IN AQUEOUS SODIUM BROMIDE AT DIFFERENT TEMPERATURES
}

\author{
V. A. Giratkar ${ }^{*}$, R. B. Lanjewar ${ }^{2}$ and S. M. Gadegone ${ }^{3}$ \\ ${ }^{1}$ Departme nt of Chemis try, Sardar Patel College, Chandrapur, 442403, Maharashtra, India \\ ${ }^{2}$ De partment of Che mistry, M.P. Deo Me morial Science College, Nagpur, Maharashtra, India \\ ${ }_{3}^{3}$ Departme nt of Chemistry, Kamla Nehru College, Nagpur, Maharashtra, India \\ giratkar.vandana@gmail.com
}

\section{Abstract}

The ultrasonic ve locity $(\mathrm{u})$, density $(\rho)$ and vis cosity $(\eta)$ of an amino acid L-Valine of various concentrations in $2 \%$ of $\mathrm{NaBr}$ solutions have been measured. From these experimentally measured parameters thermodynamic parameters such as adiabatic compressibility $\left(\beta_{\mathrm{a}}\right)$, intermolecular free length $\left(\mathrm{L}_{\mathrm{f}}\right)$, acoustic impedance $(Z)$ and internal pressure $\left(\pi_{i}\right)$ we re calculated. It was found that there is certain degree of variation in these parameters with change in concentration and temperature. The variations of acous tic parameters with concentration and te mpe rature indicate the existence of intermolecular in te raction in the present systems.

Ke ywords: L-Valine, Ultras onic velocity, thermodynamic parameters, molecular in teractions

\section{INTRODUCTION}

Salts have large effects on the structure and properties of proteins [1]. Proteins are the most abundant biomolecules of the living system of all the organic compounds. They are needed for the most important biological processes like cell growth and their maintenance, movement and defense. Proteins are complex molecules and their behavior in solutions is governed by a combination of many specific interactions [2, 3]. These interactions are mainly those between the protein molecules and the solvent ions. Most of these interactions such as hydrogen bonding, electrostatic interactions, hydrophobic interaction etc., are non-covalent. The study of these interactions provides an important insight into the conformational stability and unfolding behavior of globular proteins. Due to complex molecular structure of prote ins, the ir dire ct study is difficult and tedious. One approach that reduces the degree of complexity and requires less complex measurements techniques is to study the interactions in systems containing model compounds such as amino acids and peptides [4-6]. The standard a-amino acids have special importance among the other chemical groups since they are found in all naturally occurring proteins, which play a vital role in ne arly all che mical and biological process. There has been an increased interest in physicochemical properties of amino acids in aqueous and aqueous electrolytes media [7-12] L-Valine is an essential non-polar amino acid. It helps to remove extra nitrogen from liver and also stimulate muscle growth and the central nervous system. Deficiency of L-Valine causes degenerative nerve diseases. Many researchers have reported the physico-chemical properties of amino acids [13-18] but very scanty work on solution of amino acid in aqueous and aqueous electrolyte solutions.

\section{MATERIALS AND METHODS}

The compound L-Valine CAS No. 72-18-4, molecular weight 117.146 was obtained from HIMEDIA India Ltd. The purity of compound is $99 \%$. It was used as supplied. Initially $2 \%$ aqueous $\mathrm{NaBr}$ stock solution was prepared by using double distilled water. The digital balance having an accuracy of $\pm 0.1 \mathrm{mg}$ was used for the measurement of weights. The fresh L-Valine solutions under the study of different concentration in the given solvent were prepared. The densities of aqueous solvent and solution of different concentration $(0.02 \mathrm{M}$ to $0.12 \mathrm{M})$ at different temperature range $\mathrm{T}=(288.15$ to $303.15) \mathrm{K}$ were measured by specific gravity bottle by relative measurement method with accuracy of $\pm 0.1 \quad \mathrm{~kg} \cdot \mathrm{m}^{-3}$. During the measure ment of densities temperature was kept constant by using digital constant temperature water bath having an accuracy of $\pm 0.1 \mathrm{~K}$. Owing to the importance of Ostwald's viscometer for the measure ment of viscosity, the viscosity of solvent and solution under the study was measured. The ultrasonic velocity of solvent and solution of different concentration at different temperature range $(288.15 \mathrm{~K}$ to $303.15 \mathrm{~K})$ was measured by using digital ultrasonic interferomete $r$ at frequency $2 \mathrm{MHz}$ (VI Microsystems Pvt. Ltd. Perungudi, Che nnai) with an accuracy of $\pm 0.1 \%$. The temperature of solution was kept constant during each measure ment.

\section{PHYSICAL PARAMETERS}

Using experimentally measured basic parame te rs such as density, viscosity and ultraso nic velocity various the rmodynamic parameters are evaluated by using the following mathematical equations. 
Ad iabatic compressibility $(\beta)$

$\beta=\frac{1}{\rho U^{2}}$

Where $\rho$ and $U$ are the density and ultrasonic velocity of solution

Intermolecular free length $\left(\mathrm{L}_{\mathrm{f}}\right)$

$\mathrm{L}_{\mathrm{f}}=\mathrm{K} \beta^{1 / 2}$

Where, $\mathrm{K}$ is Jacobson's constant.

This constant is a temperature dependent parame te $r$ whose value at any te mperature $(\mathrm{T})$ is give $n$ by $(93.875+0.345 \mathrm{~T}) \times 10^{-8}$.

Acoustic impedance $(Z)$

$Z=U \rho$

Internal pressure $\left(\pi_{\mathrm{i}}\right)$

$\pi_{\mathrm{i}}=\operatorname{bRT}\left(\frac{\mathrm{K \eta}}{U}\right)^{1 / 2}\left(\frac{\rho^{2 / 3}}{M_{e f f}}\right)^{7 / 6}$

Where,

b - stands for cubical packing, which is assumed to 2 for all the liquids

$\mathrm{K}$ - is a dimensionless constant independent of tempe rature
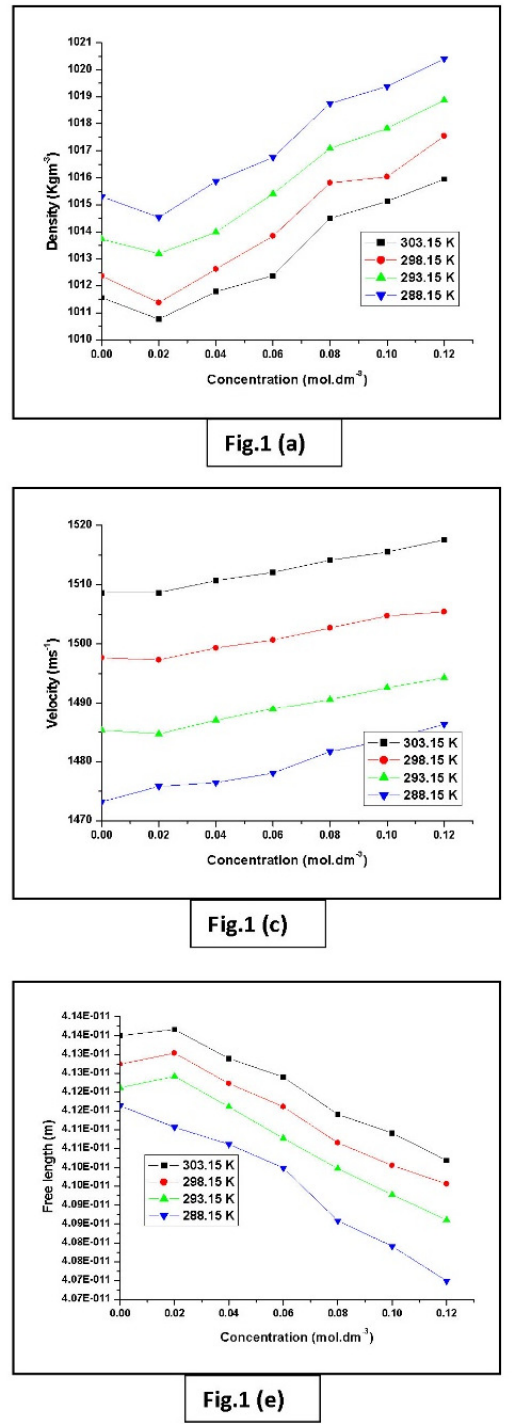

$\mathrm{T}$ - is the absolute te mperature in Kelvin $M_{\text {eff }}$ - is the effective molecular weight

$\mathrm{R}$ - is gas constant

RESULT AND DISCUSSION

The variation of experimentally measured and derived thermoacoustic parameters of solution of L-Valine in $2 \%$ aqueous solution of sodium salt of different concentration (0.02 to 0.12$) \mathrm{mol} \mathrm{dm}^{-3}$ at different te mperature range $\mathrm{T}=(288.15,293.15$, 298.15 and 303.15) $\mathrm{K}$ are as given in fig. a-g.

Fig. 1(a) shows that de nsity of L-Valine solution in $2 \%$ aqueous $\mathrm{NaBr}$ increases with increase in concentration of solution; however it falls with the increase in temperature. This result is obvious as the volume of the solution increases with the rise in temperature [19] and mass of the solution increase with the increase in concentration.
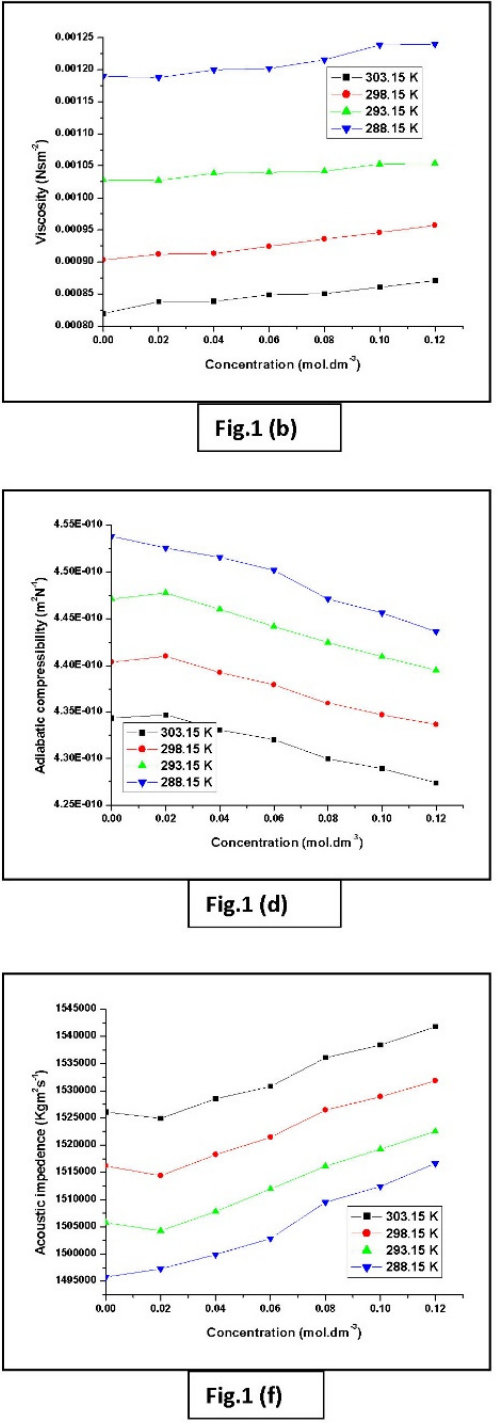


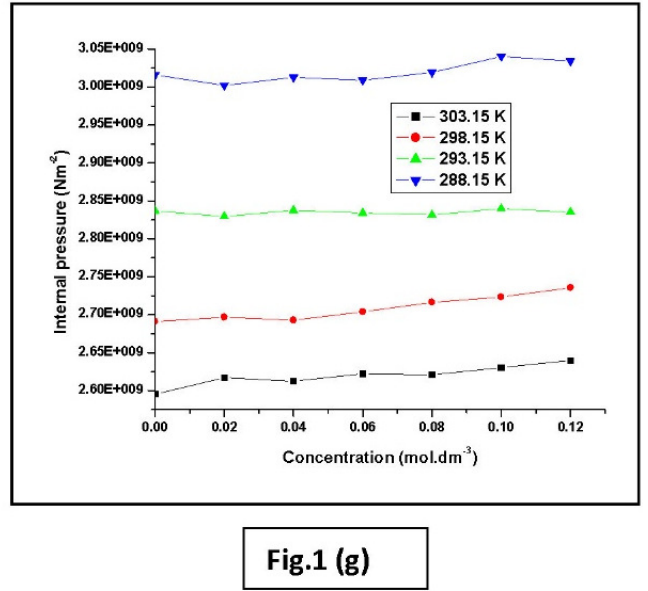

Viscosity is the parameter of the liquid, which is greatly affected by the concentration and the temperature. It is observed from fig. 1(b), that viscosity of L-Valine solution in $2 \%$ aqueous electrolytes increases with increase in concentration and decreases with increase in temperature. Increase in viscosity of solution with concentration suggests the strong interaction of solute and solvent molecule. With the rise in temperature molecules in the solution acquires more and more thermal energy. The motion of molecules increases at the expense of cohesive forces acting between the molecules. Since the solution faces lesser resistance to flow, the viscosity of the solution will decrease [20].

The increase in ultrasonic velocity with concentration (fig. 1c) in any solution indicates the presence of solute-solvent interactions [21]. The increase in ultrasonic velocity with rise in concentration for the present system confirms the greater molecular association. As temperature increases, breaking of hydrogen bonding increases. This results in more and more number of monomeric water molecules. These molecules then enter in the cage-like wate $r$ structure and get trapped to form closed packed structure. This closed-packed structure forms stiff material medium for the propagation of ultrasonic wave. Hence ultrasonic velocity increases with the rise in te mperature.

The dependence of adiabatic compressibility of LValine solutions in 2\% aqueous solution of sodium bromide on concentration at different temperature is as shown in the fig. $1(\mathrm{~d})$. The decrease in adiabatic compressibility values with concentration indicate that the hydrogen bonding between the unlike components in the solution decreases [22]. Adiabatic compressibility is inversely correlated with ultrasonic velocity which increases with increase in temperature. Hence adiabatic compressibility values decreases with increase in temperature.
The decrease in free length (fig. 1e) with rise in concentration of $\mathrm{L}-\mathrm{V}$ aline solution in $2 \%$ aque ous electrolytic solution suggest that there is a significant interaction between solute and solvent molecules. It also suggests the structure promoting behavior [23, 24] as well as the presence of dipole-dipole and acceptor-donor interaction between solute and solvent molecules. The higher values of free length for higher temperature are due to more spacing among the components of the medium.

Acoustic impedance depends on the density of the medium and the speed of the sound wave. Fig.1 (f) shows the variation of acoustic impedance with concentration and te mperature. The increase in acoustic impedance with the increase in concentration as well as temperature suggests the greater association of solute and solvent through hydrogen bonding. Thus increase in acoustic impedance indicates associative nature of solute and solvent and enhancement in molecular interaction.

The internal pressure is the cohesive force or binding force, which is a resultant force of attraction and repulsion between the molecules. From fig. $1(\mathrm{~g})$ it is observed that decrease in internal pressure with increase in te mperature is due to the thermal agitation of molecules which reduces the interaction between the molecules in the system.

\section{CONCLUSIONS}

Basic physical parameters such as ultrasonic velocity, density and viscosity of LValine solution in $2 \%$ aqueous salt of different concentration at different temperature were measured initially. Using these basic parame te rs various acoustical parameters were evaluated. The temperature effect on these parameters was discussed appropriately. These parame ters we re interpreted in connection with the molecular interactions. The addition of solute in solvent has structure making tendency through intermolecular hydrogen bonding.

\section{REFERENCES}

[1] Von Hippel, P. H. and Schleich, T. (1969): Ion effect on the solution structure of biological macromolecules. Acc. Chem. Res., vol 2: Pp 257265.

[2] Thirumaran, S. and Sathish, K. (2011): Molecular interionic interaction studies of some divalent transition metal sulphates in aqueous e thylene glycol at different temperatures. Res. J. Chem. Sci., vol 8: Pp 63-71.

[3] Thirumaran, S. and Mary Christina Gardilya, D. (2011): Volumetric and ultrasonic studies on interionic interactions of some amino acids in aqueous magnesium acetate medium at 
306.15K. Rec. Res. Sci. and Tech., vol3(8): Pp 5663.

[4] Banipal, T. S., Kaur, J. and Banipal P. K (2008): Study of interactions between amino acids and zinc chloride in aqueous solutions through volumetric measurements at $\mathrm{T}=(288.15$ to 318.15$)$ K. J. Chem. Eng. Data., vol 53: Pp 1803-1816.

[5] Pal, A. and Kumar, S. (2005): Volumetric properties of L-alanine, and L-valine in aqueous sucrose solutions at $\mathrm{T}=(288.15$ and 308.15$) \mathrm{K}$. J . Chem. Thermodyn., vol 35: Pp 1085-1092.

[6] Nain, A. K. and Chand, D. (2009): Volumetric, ultrasonic, and viscometric behavior of glycine, DL-alanine, and L-valine in aqueous 1,4bu tanediol solutions at diffe re nt tempe ratures.J. Chem. Thermodyn., vol 41: Pp 243-249.

[7] Pinho, S. P. (2008): Water Activity in Aqueous Amino Acid Solutions, with and without $\mathrm{KCl}$, at 298.15 K. J. Chem. Eng. Data., vol 53: Pp 180184.

[8] Wang, J. and Feng, R. (1990): Ultrasonic velocity of aqueous solutions of amino acids, Ultras onics. vol 128: Pp 37-39.

[9] Thirumaran, S. and Sabu, K. J. (2009): Ultrasonic investigation of amino acids in aqueous sodium acetate medium. Ind. J. pure and Appl. Phys., vol 47: Pp 87-96.

[10] Sumathi, T. and Varalakshmi, M. (2010): Ultrasonic velocity, density and viscosity measurement of methionine in aqueous electrolytic solutions at 303K. Rasayan J. Chem., vol 3(3): Pp 550-555.

[11] Thirumaran, S. and Kannappan, A. N. (2009): Volumetric and ultrasonic studies of some amino acids in aqueous sodium butyrate solution. Global J. Mol. Sci., vol 4: Pp 160-166.

[12] Riyazuddeen, and Basharat, R. (2006): Intermolecular/ interionic interactions in 1isoleucine, 1-proline, and lglutamine-aqueous electrolyte systems. J. Chem. Thermodyn., vol 38: Pp 1684-1695.

[13] Nagaraj, S., Subha, M.C.S., Nagamani, C. and Chowdoji Rao K. (2016): Ultrasonic velocity studies of amino acids in aqueous tertia ry butyl alcohol at 303.15K. World J. Pharm. and Pharmace. Sci., vol 5(1): Pp 1423-1441.

[14] D' Souza, R. and Meenakshi, G. (2015): Investigation of molecular in te raction of amino acids in aqueous n-propanol solutions at 308.15
K. Int. J. Res. Engi. and Techn., vol 4(1): Pp 96100.

[15] Sathish, M. and Meenakshi, G. (2014): Ultrasonic study of some amino acids in aqueous salt solution of KNO3 at $303.15 \mathrm{~K}$. Int. J. Res. Engi. and Techn., vol 3(2): Pp 312-317.

[16] Sarvazyan, A. P. and Chalikian, T. V. (1990): A coustic nonlinearity parameter B/A of aqueous solutions of some amine acids and proteins. J. Acoust. Soc. Am., vol 88(3): Pp 1555-1561.

[17] Riyazuddeen, and Khan I. (2008): Vis cosity studies of (L-alanine-, L-proline, L-valine, Lleucine + aqueous $\mathrm{KCl} / \mathrm{KNO} 3$ ) solutions at different te mperature s. J. Chem. Thermodyn., vol 40: Pp 1549-1551.

[18] Sumathi, T. and Alphonsa, K. J. (2013): Densities and speeds of sound of L-valine in aqueous sodium bromide solutions at various temperatures. Global Research Analysis, vol 2(8): Pp 172-174.

[19] Rajathi, K., Ali, S. J. and Rajendran, A. (2011): Ultrasonic study of molecular dynamics in some binary mixtures. J. Chem. Pharm. Res., vol3 (5): Pp 348-358.

[20] Kaur, K. and Kumar, H. (2013): Viscometric measurements of L-serine with antibacterial drugs ampicillin and amoxicillin at different temperature s: (305.15 to 315.15$)$ K. J. Mol. Liq., vol 177: Pp 49-53.

[21] Godhani, D. R., Dobariya, P. B. and Sanghani, A. M (2012): Effect of te mperature and solvents on ultrasonic velocity and the rmodynamic parameters of 1, 3, 4-oxadiazole derivative solutions. J. Mol. Liq., vol 168: Pp 2835.

[22] Iqbal, M. and Verrall, R. E. (1989): Apparent molar volume and adiabatic compressibility studies of aqueous solutions of some drug compounds at $25^{\circ} \mathrm{C}$. Can. J. Che m., vol 67 (4): Pp 727-735.

[23] Kanhekar, S., Pawar, P. and Bichile, G. (2010): Thermodynamic properties of electrolytes in aqueous solution of glycine at different temperatures. Ind. J. Pure and Appl. Phys., vol 48: Pp 95-99.

[24] Sethu Raman, M., Ponnuswamy, V., Kolandaive1, P. and Perumal, K. (2010): Ultrasonic and DFT study of intermolecular association through hydrogen bonding in aqueous solutions of $\mathrm{d}(-)$ arabinose. J. Mol. Liq. vol 151: Pp 97-106. 